\title{
Special issue: Local landscape planning and management in rural areas
}

\section{Chun-Yen Chang ${ }^{1}$}

Published online: 15 June 2021

○ International Consortium of Landscape and Ecological Engineering 2021

Rural areas, along with urban ones, represent a major zone of land human use, as well as playing an important role for wildlife's habitats. However, rural land uses are threatened by the rapid development of landscapes by people, particularly the development of private land (Theobald et al. 2000; Travis et al. 2002). There are several main topics that we, as researchers, must focus on to face these problems. The first is the policies that exist for rural resource management and land use in rural areas. These policies proposed by central and local governments will significantly impact the future development of the rural ecosystem; species' habitats should be managed and protected by land-use policies. The second concern is sustainable economic development. In rural areas, sustainable development relies on sustainable economic activities. With that in mind, different stakeholders' concerns have to be taken seriously in landscape management and planning procedures. The third, adopting theories for conceptual framework of studies and developing new technologies—-such as cutting-edge monitoring systems, artificial intelligence, and big data—presents an opportunity to improve the rural environment.

\section{Ecological land-use policies}

The assessment and implementation strategies of rural landuse policies have important impacts on the landscape ecology of rural areas as, compared to urban areas, changes to rural land-use policies have longer lasting and more powerful effects on ecological systems. Policies change not only the land-use structure but also the ecosystem services

Chun-Yen Chang

cycmail@ntu.edu.tw

1 Department of Horticulture and Landscape Architecture, National Taiwan University, No. 138, Sec. 4, Keelung Rd., Taipei 106, Taiwan environments provide. For example, policy aiming for biodiversity conservation and tourism predicted the increase in forest proportion that helps carbon sequestration, whereas the prediction of the stagnant agriculture showed a decline in habitat quality and timber production in the future 50 years (Shoyama and Yamagata 2014). The habitats of outer insensitive species may thus be altered, with impacts such as these influencing wide-ranging areas, from urban fringes to mixed-used buffer zones to protected rural areas.

\section{Sustainable economics}

Willingness to pay for the protection and management of rural ecological resources is one of the most important issue affecting the sustainability of the rural environment. The long-term management on the rural ecological system must be founded on a well-balanced economic mechanism. Healthy financial support is the driving force that can maintain the protection and monitoring of the biodiversity of rural areas (Gawith and Hodge 2019). As such, knowing how to establish an economic system that can support rural communities and the agricultural production chain is an important subject for landscape researchers.

When considering the sustainable mechanisms needed in rural areas, willingness to pay is a critical point that researchers have to include in their investigations. Several factors influence the financial provision for rural resources by deciding the support for them from key stakeholders that, in the long run, will establish a mechanism of natural resource management. 


\section{Theories and technological approach}

How people perceive the ecosystem has been abundantly discussed, along with how and in what ways people benefit from human-nature interactions. Biophilia, is a term that explains the emotional attachment that is the reason why humans love nature as resulting from their immersion in nature (Wilson 1984; Kellert and Wilson 1993). Looking back, the savanna hypothesis is that previous human beings lived among savanna-like terrain with scattered trees (Balling and Falk 1982) that offered them the capacity to observe (prospect) without being seen (refuge), and thus met their needs (Appleton 1975). Relating to that, the information processing theory infers that human perceive information richness from visual stimulation, and use this to evaluate, explore, and understand their surrounding environment (Kaplan 1987). Researchers not only use psychological questionnaires to understand the perceived psychological benefits as experience in nature, such as flow experience, Qi experience, Traditional environmental Qi, etc., (Csikszentmihalyi 1990; Chou et al. 2020; Hung et al. 2021) but also have today developed state-of-art techniques to understand humans' relationship with the natural world. Using virtual reality, augmented reality, biofeedback measurements, brain scans (fMRI) (Tang et al. 2017), etc., updated technologies are being adopted to uncover how humans perceive and are physically influenced by the natural environment. Understanding these perceptive and cognitive factors helps natural resource managers to establish planning and design criteria for the natural environment.

Landscape ecology studies rely on a good ecological onsite survey, which indicates the distribution of habitats, species, surrounding landscape types, and the developed areas among humans. The researchers may delimit the research scope, the affected area, and the protected area to track the dynamic of changes from those patterns, processes, and functions. Following a good survey, trustworthy data management is critical for researchers engaging in data mining and analysis (Gustafson 1998; McGarigal and Marks 1995). Along with the updated geographic information systems, artificial intelligence (especially for image comparison and analysis), unmanned aerial vehicles, big data, and cloud datasets provide new, strong supports to researchers. For example, by applying the artificial intelligence system, researchers are able to use technology to autonomously identify species from photos (Panboonyuen et al. 2017). Their identified features can be used to make predictions or draw correlations from ecological data-such as green infrastructure rates or green cover percentages-concerning human health and wellbeing (Chang et al. 2016; Chou et al. 2016; Helbich et al. 2019;
Li et al. 2019; Suppakittpaisarn et al. 2019). Further to this, unmanned aerial vehicles (UAVs) provide alternative options for researchers to investigate the landscape types in field research, which supports researchers understand the ecological distribution and topography of the landscape immediately. Beyond that, cloud computation gives researchers the ability to collect and analyze big, long-term datasets. The adoption of both landscape metrics and machine learning techniques has been growing in rural area studies (Chakraborti et al. 2018; Liu et al. 2018). Newly developed technologies continually support innovative studies in landscape and ecological engineering.

\section{Think globally, act locally}

To manage the rapid development of rural areas, managers need to think globally and act locally. The fast-paced changes in the urban area lead to reduce the greens and blue spaces. Destroying the structure of landscape ecology and causing the unbalance between species and human beings. Every region adapts to local conditions, especially brings greens and blue spaces back in the urban. One of the methods is urban agriculture. Research into urban agriculture and public health (Brown and Jameton 2000; Okvat and Zautra 2011; Specht et al. 2014; Cohen and Reynolds 2015) strives toward (1) reducing the gap between the rich and the poor and increasing employment opportunities, (2) food safety, (3) changes in the structure of social interaction, (4) environmental education, (5) increased physical and mental health, and (7) sustainability. Sustainable practices of agricultural land management can be learned, from the local knowledge such as Satoyama concept in Japan support the value of traditional knowledge. Indigenous knowledge is built on long-term human-natural experiences. Farmers in an area know the habitat needs of local species, their food chain, and the interactions among these species. Lunar calendars are indispensable sources of information for rural residents to predict and follow the laws of nature. Respecting the local experience when considering the ecosystem in a regional landscape context helps researchers and managers to draw up wise policies for rural land use.

\section{About this special issue}

The articles of special features of "Local Landscape Planning and Management in Rural Areas" come from the 2009 Annual Conference of the International Consortium of Landscape and Ecological Engineering (ICLEE). The conference was hosted by the Chaoyang University of Technology, Taichung, Taiwan with the theme of "A Promising Future for 
Rural Areas". At the conference, the resource management of rural areas and future development issues were discussed.

The special features articles cover different topics relating to ecological land-use policies. Hui-Mei Chen, Chen-Chuan Huang, and Po-Tsung Gao publish the feasibility assessments and implementation strategies of green care in rural Taiwan. In this article, political feasibility is assessed based on social demand and government policies. The results show that green care implementing 'active aging in place' is feasible in rural areas. The focus then turns to the local experience, with Fanya Qin, Katsue Fukamachi, and Shozo Shibata studying the changes of natural resource utilization (NRU) regimes for the landscape and giving recommendations for future management plans and policymaking.

Ting-Hsuan Wang, Wan-Hsuan Wu, Li Shen, and ChiaKuen Cheng go on to discuss how we can explore the validity of immersive virtual reality techniques for studying the crowding of recreational environments. In this article, updated technologies are introduced into landscape management. Three studies are tested for differences between photos and immersed virtual reality (IVR), onsite experience and IVR, and onsite photos and the virtual environment (VE) using the IVR method. Li Shen, Li-Ya Chen, and AiTsen Su then bring up concerns around economic issues in rural resource management. To study users' willingness to pay for natural environmental conservation and protection, they adopt the commitment model to examine the efficacy of satisfaction, alternative choices, and investment scale for predicting users' environmental commitments.

\section{Challenges for rural resource management}

There are challenges for rural resource management and planning. The first is the process of rural ecological policymaking. How do policies proposed and decisions made? The key point for policymaking is to have clear goals and include the stakeholders. What is the goal of managing rural resources? How do we define these goals for a rural area? Moreover, are related stakeholders invited to join the decision-making procedure? Is the procedure designed to accommodate the viewpoints of different groups? How do one group of stakeholders' need conflict with those of another group(s)? How do those involved discuss, negotiate, and come to acceptable conclusions under the guidance and with the help of professionals?

Related rural development participatory policy research confirms that the integration of multi-agent modeling and participatory backcasting is effective as it can initiate discussions between experts and stakeholders to gather various expertise (Van Berkel and Verburg 2012). Furthermore, in rural areas, community participation through the use of participatory landscape planning is a strategy that can inform the community about the governance of local, sustainable development (Valencia-Sandoval et al. 2010).

Landscape planners and designers intend to find "accurate" solutions to projects. However, it is hard to find one "accurate" solution in real situations and more often right to find a comparatively suitable plan among alternatives. Carl Steinitz's "Framework for Theory," indicates that the scientific results could support the decision and offer great value to the environmental design process. The framework is especially powerful for providing subject focus, organizing multi-faceted research, planning projects, bridging the tension between individual and collective design, and interpreting complex decision-making (Steinitz 1990). According to this, rural resource management is a dynamic system influenced by various forces in the rural environment. The management plan should be made in accordance with the values under the goals for the environment and periodically adjusted to keep in line with those.

To conclude, a promising future for rural areas lies at the heart of landscape ecological studies and will continue to be the central theme of rural development. The aims of rural resource management, the goals of rural planning projects, concerns for local species, our understanding of traditional local knowledge, and procedures that encourage the involvement of stakeholder groups are all indispensable issues to be studied further as we look ahead. We look forward to fruitful research to come that will enrich our knowledge in the field of landscape and ecological engineering.

\section{References}

Appleton J (1975) The experience of landscape. Wiley, London

Balling JD, Falk JH (1982) Development of visual preference for natural environments. Environ Behav 14(1):5-28. https://doi.org/10. $1177 / 0013916582141001$

Brown KH, Jameton AL (2000) Public health implications of urban agriculture. J Public Health Policy. https://doi.org/10.2307/33434 72

Chakraborti S, Das DN, Mondal B, Shafizadeh-Moghadam H, Feng Y (2018) A neural network and landscape metrics to propose a flexible urban growth boundary: a case study. Ecol Ind 93:952-965. https://doi.org/10.1016/j.ecolind.2018.05.036

Chang KG, Sullivan WC, Lin YH, Su WC, CY, (2016) The effect of biodiversity on green space users' wellbeing - an empirical investigation using physiological evidence. Sustainability 8(10):1049. https://doi.org/10.3390/su8101049

Chou WY, Lee CH, Chang CY (2016) Relationships between urban open spaces and humans' health benefits from an ecological perspective: a study in an urban campus. Landsc Ecol Eng 12(2):255267. https://doi.org/10.1007/s11355-016-0295-5

Chou WY, Hung SH, Chang CY (2020) Tradition environmental Qi: using human as a sensor to capture the healthy landscape attributes. J Outdoor Recreat Study 33(4):23-49. https://doi.org/10. 6130/JORS.202012_33(4).0002

Cohen N, Reynolds K (2015) Resource needs for a socially just and sustainable urban agriculture system: lessons from New York City. 
Renew Agric Food Syst 30(1):103-114. https://doi.org/10.1017/ S1742170514000210

Csikszentmihalyi M (1990) Flow: the psychology of optimal experience. Harper \& Row, New York

Gawith D, Hodge I (2019) Focus rural land policies on ecosystem services, not agriculture. Nat Ecol Evol 3:1136-1139. https://doi. org/10.1038/s41559-019-0934-y

Gustafson EJ (1998) Quantifying landscape spatial pattern: what is the state of the art? Ecosystems 1(2):143-156. https://doi.org/10. 1007/s100219900011

Helbich M, Yao Y, Liu Y, Zhang J, Liu P, Wang R (2019) Using deep learning to examine street view green and blue spaces and their associations with geriatric depression in Beijing, China. Environ Int 126:107-117. https://doi.org/10.1016/j.envint.2019.02.013

Hung SH, Hwang CY, Chang CY (2021) Is the Qi experience related to the flow experience? Practicing qigong in urban green spaces. PLoS ONE 16(1):e0240180. https://doi.org/10.1371/journal.pone. 0240180

Kaplan S (1987) Aesthetics, affect, and cognition: environmental preference from an evolutionary perspective. Environ Behav 19(1):332. https://doi.org/10.1177/0013916587191001

Kellert SR, Wilson EO (1993) The biophilia hypothesis. Island Press, Washington, D. C.

Li D, Chian Y-C, Sang H, Sullivan WC (2019) Beyond the school grounds: links between density of tree cover in school surroundings and high school academic performance. Urban for Urban Green 38:42-53. https://doi.org/10.1016/j.ufug.2018.11.001

Liu D, Toman E, Fuller Z, Chen G, Londo A, Zhang X, Zhao K (2018) Integration of historical map and aerial imagery to characterize long-term land-use change and landscape dynamics: an objectbased analysis via random forests. Ecol Ind 95:595-605. https:// doi.org/10.1016/j.ecolind.2018.08.004

McGarigal K, Marks BJ (1995) Spatial pattern analysis program for quantifying landscape structure. Gen. Tech. Rep. PNW-GTR-351. US Department of Agriculture, Forest Service, Pacific Northwest Research Station, pp 1-122

Okvat HA, Zautra AJ (2011) Community gardening: a parsimonious path to individual, community, and environmental resilience. Am J Community Psychol 47(3-4):374-387. https://doi.org/10.1007/ s10464-010-9404-z

Panboonyuen T, Jitkajornwanich K, Lawawirojwong S, Srestasathiern P, Vateekul P (2017) Road segmentation of remotely-sensed images using deep convolutional neural networks with landscape metrics and conditional random fields. Remote Sens 9(7):680. https://doi.org/10.3390/rs9070680
Shoyama K, Yamagata Y (2014) Predicting land-use change for biodiversity conservation and climate-change mitigation and its effect on ecosystem services in a watershed in Japan. Ecosyst Serv 8:25-34. https://doi.org/10.1016/j.ecoser.2014.02.004

Specht K, Siebert R, Hartmann I, Freisinger UB, Sawicka M, Werner A, Dierich A (2014) Urban agriculture of the future: an overview of sustainability aspects of food production in and on buildings. Agric Hum Values 31(1):33-51. https://doi.org/10.1007/ s10460-013-9448-4

Steinitz C (1990) A framework for theory applicable to the education of landscape architects (and other environmental design professionals). Landsc J 9(2):136-143. Available from: https://www. jstor.org/stable/43324049. Accessed 3 Jun 2021

Suppakittpaisarn P, Jiang B, Slavenas M, Sullivan WC (2019) Does density of green infrastructure predict preference? Urban for Urban Green 40:236-244. https://doi.org/10.1016/j.ufug.2020. 126842

Tang IC, Tsai YP, Lin YJ, Chen JH, Hsieh H, Hung SH, Sullivan WC, Tang HF, Chang CY (2017) Using functional magnetic resonance Imaging (fMRI) to analyze brain region activity when viewing landscapes. Landsc Urban Plan 162:137-144. https://doi.org/10. 1016/j.landurbplan.2017.02.007

Theobald DM, Hobbs NT, Bearly T, Zack J, Shenk T, Riebsame WE (2000) Incorporating biological information into local land-use decision making: designing a system for conservation planning. Landsc Ecol 15(1):35-45. https://doi.org/10.1023/A:1008165311 026

Travis WE, Theobald DM, Fagre D (2002) Transforming the rockies: human forces, settlement patterns, andecosystem effects. In: Baron J (ed) Rocky mountain futures. Island Press, Washington, D.C., pp 1-24

Valencia-Sandoval C, Flanders DN, Kozak RA (2010) Participatory landscape planning and sustainable community development: methodological observations from a case study in rural Mexico. Landsc Urban Plan 94(1):63-70. https://doi.org/10.1016/j.landu rbplan.2009.07.018

Van Berkel DB, Verburg PH (2012) Combining exploratory scenarios and participatory backcasting: using an agent-based model in participatory policy design for a multi-functional landscape. Landscape Ecol 27(5):641-658. https://doi.org/10.1007/ s10980-012-9730-7

Wilson EO (1984) Biophilia. Harvard University Press, Cambridge 